\title{
The Associations of Family Functioning, General Well-Being, and Exercise with Mental Health among End-Stage Renal Disease Patients
}

\author{
Qi Wang', Hongjian Liu', Zheng Ren², Wenjing Xiong', Minfu $\mathrm{He}^{2}$, Nan $\mathrm{Li}^{1,3}$, Xinwen Fan², Xia Guo \\ Xiangrong $\mathrm{Li}^{2}$, Hong $\mathrm{Shi}^{2}$, Shuang $\mathrm{Zha}^{2}$, and Xiumin Zhang ${ }^{2} \bowtie$ \\ 1'Department of Epidemiology and Biostatistics, School of Public Health, Jilin University, Changchun, China \\ ${ }^{2}$ Department of Social Medicine and Health Management, School of Public Health, Jilin University, Changchun, China \\ ${ }^{3}$ The First Hospital of Qiqihar City, Qiqihar, China
}

Objective This study aims to explore the relationships of family functioning, general well-being, and exercise with psychological distress. Furthermore, we investigated the special roles of general well-being and exercise on the association between family functioning and psychological distress.

Methods Of 769 end-stage renal disease (ESRD) patients participated in the cross-sectional study which consisted of the 12 -item General Health Questionnaire (GHQ-12), the Family APGAR Scales, and the General Well-Being Schedule. The collected data were analyzed using multiple linear regression analysis and path analysis.

Results The prevalence of psychological distress was $72.3 \%$. Family functioning, general well-being and exercise were associated factors of psychological distress $(\mathrm{p}<0.05)$. The indirect effect of family functioning on psychological distress was partially mediated by general well-being (Effect $=-0.08,95 \% \mathrm{CI}=-0.11,-0.04)$. In addition, the effect of family functioning on general well-being was moderated by exercise (Index $=-0.092, \mathrm{SE}=0.033,95 \% \mathrm{CI}=-0.159,-0.029$ ).

Conclusion The prevalence of psychological distress among ESRD patients was high. Family functioning, general well-being and exercise were associated with psychological distress. Family functioning could affect psychological distress partially by affecting general wellbeing. Furthermore, exercise had a significant moderating effect on the relationship between family functioning and general well-being.

Psychiatry Investig 2020;17(4):356-365

Key Words End-stage renal disease patients, Exercise, Family functioning, General well-being, Psychological distress.

\section{INTRODUCTION}

End stage renal disease (ESRD) is defined as the most advanced stage of chronic kidney disease (CKD) with a permanent loss of normal renal function at least $90 \% .{ }^{1}$ Renal replacement therapy (RRT) is a life-sustaining treatment for ESRD patients, and it mainly includes kidney transplantation, peritoneal dialysis and hemodialysis. Hemodialysis is the pre-

Received: August 6, 2019 Revised: January 4, 2020

Accepted: February 12, 2020

$\triangle$ Correspondence: Xiumin Zhang, PhD

Department of Social Medicine and Health Management, School of Public Health, Jilin University, No. 1163 Xinmin Street, Changchun 130021, China Tel: +86-431 85619442, E-mail: zhangxiumin63@163.com

(c) This is an Open Access article distributed under the terms of the Creative Commons Attribution Non-Commercial License (https://creativecommons.org/licenses/bync/4.0) which permits unrestricted non-commercial use, distribution, and reproduction in any medium, provided the original work is properly cited. dominant treatment for ESRD patients. ${ }^{2}$ In addition to the suffering caused by the disease and its complications, patients undergoing hemodialysis need to bear enormous economic pressure. "Psychological distress" is often used as an indicator of mental health. It is applied to a range of undifferentiated symptoms, from anxiety to depression, which cause emotional suffering. ${ }^{3}$ The incidence of psychological distress in hemodialysis patients was ranged from $30 \%$ to more than $50 \%$ in previous studies. ${ }^{4,5}$ Psychological distress has undesirable implications for health and quality of life, such as negatively affecting clinical outcomes and increasing the risk of mortality for hemodialysis patients. ${ }^{6,7}$ In addition, patient's psychological distress will increases burden of family and consumption of social health resources.

Researcher and clinicians need to focus on family functioning as disease affects the whole family not just the patient. The 
diagnosis of ESRD is a very stressful event for the patients and their families as they must adapt to the shock and uncertainty that such a diagnosis presents. A fairly strong relationship between family functioning and psychological distress has been confirmed by relevant studies..$^{8-10}$ One model of family functioning indicated that there is a direct relationship between family functioning and psychological distress, ${ }^{11}$ however, other model have proposed that there are variables mediating the relationship between family functioning and psychological distress. ${ }^{12}$ How and when family functioning affects psychological distress are important and deserve further study. General wellbeing comprises people's longer-term levels of pleasant affect, unpleasant affect, and life satisfaction. ${ }^{13}$ Several studies have shown a correlation between family functioning and general well-being, and the level of family functioning affected the level of general well-being. ${ }^{14,15}$ Furthermore, several studies have examined the relationship between general well-being and mental health. Burns et al. ${ }^{16}$ supported that general well-being mediated the relationship of psychological health components (resilience and mastery) and depression and anxiety, as well as it affected individuals' vulnerability to depression and anxiety. Another scholar found that general well-being was an effective predictor of resilience and mental health and that general wellbeing can mediate the relationship between resilience and mental health. ${ }^{17}$ Cognitive psychology believes that there is not a simple relationship between "stimulus and reaction" but that the relationship is "stimulus -- cognitive -- reaction." ${ }^{18}$ Based on the theory of "stimulus -- cognitive -- reaction," we hypothesis that family dysfunctionality will decrease the level of general well-being, and increase the risk of an individual's psychological distress. General well-being may mediate the relationship between family functioning and psychological distress.

There has been an increasing interest in the role of exercise in the prevention and treatment of mental health problems. Some literature supported that exercise benefits to psychological health status and plays a part in relieving symptoms of psychological disease. ${ }^{19-21}$ This is in line with the broadenand-build theory of positive emotions. Positive events and emotions have been shown to contribute to improve their general well-being, not just as an end-states in patients, but also as a means to improve psychological and physical health over time.22 The process of emotion regulation is a constantly changing "movement system," ${ }^{23}$ that is related to changes in psychology, physiology, and behavior. The notion that individuals can use exercise as a strategy to help themselves regulating mood status is founded on theories of mood-regulation. ${ }^{24,25}$ Thus, we proposed a second hypothesis that the relationship between family functioning and psychological distress is moderated by exercise. Nevertheless, how exercise directly or indirectly moderates associations among family functioning, general well-being, and psychological distress remains uncertain.

Based on these studies and theories, the aims of this study were to: 1) describe the prevalence of psychological distress of ESRD patients; 2) examine the associations of family functioning, general well-being, exercise and psychological distress; and 3) clarify the roles of general well-being and exercise on the relationship between family functioning and psychological distress.

\section{METHODS}

\section{Participants}

Participants were ESRD patients undergoing hemodialysis and were recruited from 25 hospitals in Qiqihar City in northeast China, from March to July 2018. The well-trained doctors and nurses were used as data collectors and guided participants in the completion of paper questionnaires in the hospital. All patients were asked to self-complete the questionnaire. Participants who expressed difficulty in completing the questionnaire answered questionnaire items verbally. Then, collector filled out the questionnaire. The ESRD patients in the study were clearminded and understood their own disease-related conditions. Patients were excluded from the study if they had been hemodialysis for less than 3 months or if their age was less than 18 years old. After expressing the aim of study to patients and obtained informed consent, the patients were asked to complete the study questionnaires. A total of 870 questionnaires were handed out and 854 were returned. Then, 85 patients were excluded because they had other diseases that had a great impact on mental health (cancer, ${ }^{26,27}$ stroke, ${ }^{28}$ and disability ${ }^{29}$ ). A final sample size was 769 for the present analysis. This study has received approval from the Research Ethical Committee of Jilin University (Reference Number: 2017-12-18).

\section{Instruments}

\section{2-item General Health Questionnaire (GHQ-12)}

The mental health status of the patients was assessed using the Chinese version of 12-item General Health Questionnaire that was revised by the Taiwanese scholar Taian Cheng. ${ }^{30}$ It was based on the original GHQ compiled by Goldberg. ${ }^{31}$ It does not give a diagnosis, but can identify people who have "probable mental health problems," mainly those with depression, anxiety or both..$^{32}$ The GHQ-12 includes six "negative" questions with responses ranging from "Not at all," "No more than usual," "Rather more than usual" to "Much more than usual." There also contains six "positive" questions, with possible responses in the reverse order of "negative" questions. ${ }^{33}$ The GHQ-12 scale are scored in binary format $(0-0-1-1)$. The total score ranges 
from 0 to 12, and higher scores indicate psychological problems. GHQ-12 scores of four and above indicate a trend of psychological distress. ${ }^{34,35}$ It is a brief, reliable, and valid instrument. The GHQ-12 has been validated in ESRD patients with good internal reliability and external validity in previous study. ${ }^{36}$ The coefficient of Cronbach's a of this scale in present study was 0.783 .

\section{Family APGAR Scale}

The Family APGAR Scale was developed by Smilkstein, ${ }^{37}$ and the Chinese version of Family APGAR was used for the self-reporting of patient's family functionality. ${ }^{38}$ This scale assesses the perception of family functioning through an exploration of the satisfaction degree in the relations that patient have with their relatives. It has five items that measure individual's satisfaction with the characteristics of the family: adaptation, partnership, growth, affection, and intimacy. People select how often they are satisfied with aspects of the family on three-point scales extending from 0 (rarely) to 2 (always). The final family functioning score is the sum of all five items. The total score of the Family APGAR ranges from 0 to 10 , with higher scores indicating a more highly functional family. ${ }^{39}$ Specifically, Family APGAR score of $0-3$ is considered to be high dysfunctionality, 4-6 is moderate dysfunctionality, and 7-10 is good functionality. ${ }^{40}$ In the present study, the Cronbach's a coefficient of the Family APGAR scale was 0.889 .

\section{General Well-Being Schedule (GWB)}

General well-being was measured by the General Well-Being Schedule. It was translated and revised by Chinese scholar. ${ }^{41}$ The schedule consisted of 18 items measures the extent to which an individual feels good or content with their life as a whole. The first 14 items use a six-point scale that represents either intensity or frequency (except for the 2, 5, 6, and 7 which use a five-point rating scale), and the remaining items use a $0-10$ rating scale. Items $1,3,6,7,9,11,13,15$, and 16 are reverse scored. ${ }^{42}$ The total score obtained by summing the scores across each of the 18 items is ranging from 0 to 110 . High score reflect a high level of general well-being. ${ }^{43}$ The Cronbach's a coefficient of the GWB has been found to be 0.816 .

\section{Demographics}

Demographics included age, sex, marital status, smoking habit (those who have smoked continuously or cumulatively for six or more months during their lifetime and who have smoked in the past 30 days), drinking habit (those who have been drinking at least once a week for more than a year), exercise (yes: the frequency of aerobic physical exercise more than four times a month, no: a frequency of aerobic physical exer- cise less than four times a month), hobby (widely, general, not extensive), sleeping time ( $<7,7-8$, and $>8 \mathrm{~h} /$ night), sleep disturbance (self-perceived bad/worse sleep conditions or those who needed drug-assisted sleep were considered to have sleep disturbance), self-rated health (better, general, poor), life satisfaction (satisfied, general, not satisfied), hemodialysis frequency $(<3,3$, and $>3$ times/week), self-care ability (fully self-care, partially self-care, can't self-care), caregivers (relatives, nonrelatives). The characteristics of the participants are reported in Table 1.

\section{Statistical analyses}

Continuous variables with a normal distribution are presented as the mean \pm standard deviations (SD), those with a nonnormal distribution are presented as medians (interquartile ranges), and categorical variables are shown as number (percentages). We conducted descriptive and correlation analyses for the study variables. Analysis of variance (ANOVA) were used for variables of age and general well-being, and KruskalWallis $\mathrm{H}$ tests were used for the variables years on hemodialysis and GHQ-12 score. Other variables were used chi-square test to assess the differences in basic characteristics according to the categorized family functioning. The intercorrelations between the investigated variables were examined by Pearson correlation analysis and intraclass correlation coefficients.

Multiple linear regression analysis was used to examine whether general well-being mediated the association between family functioning and psychological distress. Then, the PROCESS macro method (Model 4) was adopted further to reconfirm the mediation and to perform the bootstrap method. The number of bootstrap samples was 5,000. On the acceptance of Hypothesis 1, group regression analysis was used to examine whether the association among family functioning, general well-being and psychological distress was moderated by exercise. Then, the PROCESS macro method (Model 7) was adopted to further test and verify the moderated mediation model. We calculated 95\% bootstrap confidence intervals (CI) based on 5,000 bootstrapped samples. All p-values are twosided, and a p-value of less than 0.05 was considered statistically significant. Statistical analyses was performed with IBM SPSS 24.0 (IBM Corp., Armonk, NY, USA).

\section{RESULTS}

\section{Basic characteristics}

Of 769 ESRD patients undergoing hemodialysis, male and female patients accounted for $57.6 \%$, and $42.4 \%$ respectively, and their ages ranged from 18 to 94 years (mean $=51.54$ years, $\mathrm{SD}=14.47$ ). The prevalence of psychological distress (GHQ-12 score $\geq 4$ ) was $72.3 \%$ (556/769). Table 1 showed the basic characteristics of the participants (demographic characteristics, 
Q Wang et al.

Table 1. Descriptive characteristics of participants by family functioning

\begin{tabular}{|c|c|c|c|c|c|}
\hline \multirow[b]{2}{*}{ Variables } & \multirow{2}{*}{$\begin{array}{l}\text { Sample } \\
(\mathrm{N}=769)\end{array}$} & \multicolumn{3}{|c|}{ Family functioning } & \multirow[b]{2}{*}{$\mathrm{p}$ value } \\
\hline & & $\begin{array}{l}\text { Good functionality } \\
\qquad(\mathrm{N}=419)\end{array}$ & $\begin{array}{l}\text { Moderate dysfunctionality } \\
\qquad(\mathrm{N}=287)\end{array}$ & $\begin{array}{l}\text { High dysfunctionality } \\
\qquad(\mathrm{N}=63)\end{array}$ & \\
\hline Age, year* & $53.13 \pm 16.24$ & $54.28 \pm 16.42$ & $51.22 \pm 15.64$ & $54.20 \pm 17.14$ & 0.042 \\
\hline Gender $^{\dagger}$ & & & & & 0.007 \\
\hline Male & $443(57.6)$ & $254(60.6)$ & $146(50.9)$ & $43(68.3)$ & \\
\hline Female & $326(42.4)$ & $165(39.4)$ & $141(49.1)$ & $20(31.7)$ & \\
\hline Marriage $^{\dagger}$ & & & & & $<0.001$ \\
\hline Married & $533(69.3)$ & $316(75.4)$ & $175(61.0)$ & $42(66.7)$ & \\
\hline Non-married & $236(30.7)$ & $103(24.6)$ & $112(39.0)$ & $21(33.3)$ & \\
\hline Smoking ${ }^{\dagger}$ & & & & & 0.291 \\
\hline No & $553(71.9)$ & $303(72.3)$ & $210(73.2)$ & $40(63.5)$ & \\
\hline Yes & $216(28.1)$ & $116(27.7)$ & $77(26.8)$ & $23(36.5)$ & \\
\hline Drinking $^{\dagger}$ & & & & & 0.524 \\
\hline No & $590(76.7)$ & $326(77.8)$ & $219(76.3)$ & $45(71.4)$ & \\
\hline Yes & $179(23.3)$ & $93(22.2)$ & $68(23.7)$ & $18(28.6)$ & \\
\hline Exercise $^{\dagger}$ & & & & & 0.039 \\
\hline No & $322(41.9)$ & $167(39.9)$ & $135(47.0)$ & $20(31.7)$ & \\
\hline Yes & $447(58.1)$ & $252(60.1)$ & $152(53.0)$ & $43(68.3)$ & \\
\hline Hobby $^{\dagger}$ & & & & & $<0.001$ \\
\hline Widely & $221(28.7)$ & $95(22.7)$ & $108(37.6)$ & $18(28.6)$ & \\
\hline General & $478(62.2)$ & $265(63.2)$ & $171(59.6)$ & $42(66.7)$ & \\
\hline Not extensive & $70(9.1)$ & $59(14.1)$ & $8(2.8)$ & $3(4.8)$ & \\
\hline Sleeping time ${ }^{\dagger}$ & & & & & 0.021 \\
\hline$<7 \mathrm{~h} /$ night & $438(57.0)$ & $227(54.2)$ & $168(58.5)$ & $43(68.3)$ & \\
\hline $7-8 \mathrm{~h} /$ night & $280(36.4)$ & $169(40.3)$ & $98(34.1)$ & $13(20.6)$ & \\
\hline$>8 \mathrm{~h} /$ night & $51(6.6)$ & $23(5.5)$ & $21(7.3)$ & $7(11.1)$ & \\
\hline Sleep disturbance ${ }^{\dagger}$ & & & & & $<0.001$ \\
\hline No & $458(59.6)$ & $299(71.4)$ & $130(45.3)$ & $29(46.0)$ & \\
\hline Yes & $311(40.4)$ & $120(28.6)$ & $157(54.7)$ & $34(54.0)$ & \\
\hline Self-rated health ${ }^{\dagger}$ & & & & & 0.001 \\
\hline Better & $100(13.0)$ & $73(17.4)$ & $18(6.3)$ & $9(14.3)$ & \\
\hline General & $464(60.3)$ & $239(57.0)$ & $190(66.2)$ & $35(55.6)$ & \\
\hline Poor & $205(26.7)$ & $107(25.5)$ & $79(27.5)$ & $19(30.2)$ & \\
\hline Life satisfaction $^{\dagger}$ & & & & & $<0.001$ \\
\hline Satisfaction & $144(18.7)$ & $107(25.5)$ & $31(10.8)$ & $6(9.5)$ & \\
\hline General & $406(52.8)$ & $207(49.4)$ & $164(57.1)$ & $35(55.6)$ & \\
\hline Not satisfied & $219(28.5)$ & $105(25.1)$ & $92(32.1)$ & $22(34.9)$ & \\
\hline Dialysis age, year $\ddagger$ & $3.3(1.8,6.2)$ & $3.3(1.8,5.8)$ & $3.3(2.0,6.5)$ & $4.5(1.9,6.8)$ & 0.238 \\
\hline Dialysis frequency $^{\dagger}$ & & & & & $<0.001$ \\
\hline$<3$ times/week & $112(14.6)$ & $29(6.9)$ & $76(26.5)$ & $7(11.1)$ & \\
\hline 3 times/week & $646(84.0)$ & $384(91.6)$ & $206(71.8)$ & $56(88.9)$ & \\
\hline$>3$ times/week & $11(1.4)$ & $6(1.4)$ & $5(1.7)$ & $0(0.0)$ & \\
\hline
\end{tabular}


Table 1. Descriptive characteristics of participants by family functioning (continued)

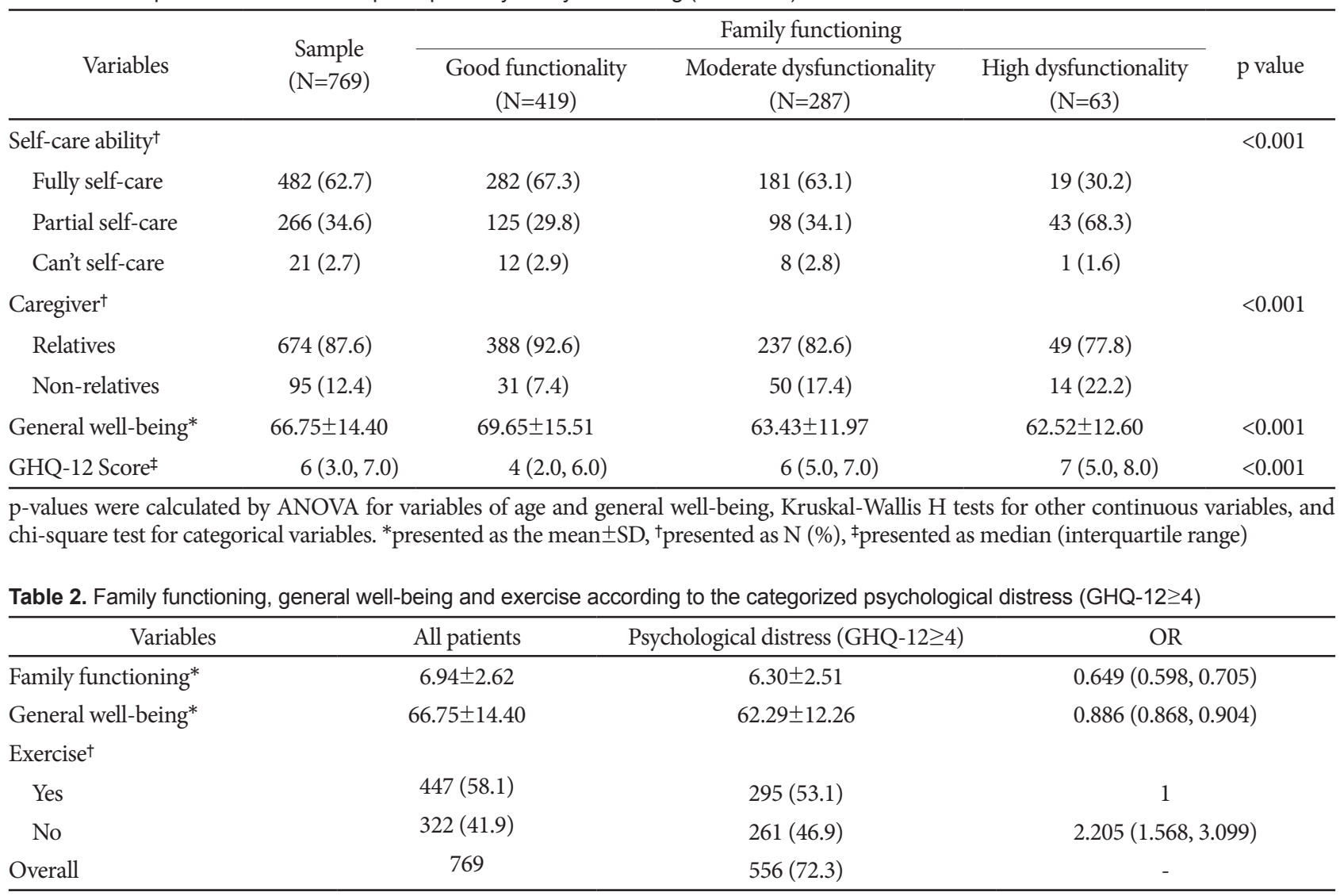

High score reflects a high level of family functioning and general well-being. * presented as the mean \pm SD, ${ }^{\dagger}$ presented as $\mathrm{N}(\%)$

Table 3. Descriptive statistics and correlations among variables

\begin{tabular}{lcccccc}
\hline \multicolumn{1}{c}{ Variables } & $\mathrm{M}$ & $\mathrm{SD}$ & $(1)$ & $(2)$ & $(3)$ & $(4)$ \\
\hline (1) Family functioning & 6.94 & 2.62 & 1 & & & \\
(2) General well-being & 66.75 & 14.40 & $0.281^{*}$ & 1 & & \\
(3) Psychological distress & 5.04 & 2.74 & $-0.411^{*}$ & $-0.661^{*}$ & 1 & \\
(4) Exercise & - & - & 0.063 & $0.177^{*}$ & $-0.201^{*}$ & 1 \\
\hline
\end{tabular}

GHQ-12 scores of four and above indicates tendency of psychological distress. ${ }^{*}$ statistical significance: $\mathrm{p}<0.001$

disease-related status, general well-being score and GHQ-12 score) according to the categorized family functioning. Three categories described the level of family functioning: a family APGAR score of 0-3 suggests high dysfunctionality, 4-6 moderate dysfunctionality, and 7-10 good functionality. Statistical significance was observed for the distribution of all characteristics except for smoking habits, drinking habits and years on hemodialysis among different family functioning groups.

\section{Preliminary analyses}

Of all patients, $72.3 \%$ patients reported having a psychological distress. A higher level of family functioning ( $O R=0.649$,
$95 \% \mathrm{CI}=0.598,0.705)$, and general well-being $(\mathrm{OR}=0.886$, $95 \% \mathrm{CI}=0.868,0.904)$ can decrease the risk of psychological distress among ESRD patients. Individuals who did not do physical exercise were 2.205 ( $95 \% \mathrm{CI}=1.568,3.099)$ times as likely to have psychological distress than those who did physical exercise. Data was shown in Table 2.

As shown in Table 3, means, standard deviations and correlation coefficients among study variables were presented separately. As anticipated, family functioning, general wellbeing were negatively correlated with psychological distress $(\mathrm{p}<0.001)$. In contrast, family functioning was positively correlated with general well-being $(\mathrm{p}<0.001)$. Compared with patients who did not do physical exercise, patients who did 
Table 4. Mediated regression analysis for family functioning and general well-being as predictors of mental health

\begin{tabular}{|c|c|c|c|c|c|}
\hline Variable & $\mathrm{B}$ & $\beta$ & $\mathrm{t}$ & $\mathrm{R}^{2}$ & $\mathrm{~F}$ \\
\hline \multicolumn{6}{|c|}{ Step 1. Family functioning predicts general well-being } \\
\hline Independent variable: family functioning & 0.819 & 0.149 & $4.966^{*}$ & 0.43 & $38.49^{*}$ \\
\hline \multicolumn{6}{|l|}{ Dependent variable: general well-being } \\
\hline \multicolumn{6}{|c|}{ Step 2. Family functioning predicts psychological distress } \\
\hline Independent variable: family functioning & -0.291 & -0.278 & $-8.889 *$ & 0.38 & $31.02^{*}$ \\
\hline \multicolumn{6}{|l|}{ Dependent variable: psychological distress } \\
\hline \multicolumn{6}{|c|}{ Step 3. Control family functioning, general well-being predicts psychological distress } \\
\hline Independent variable: family functioning & -0.214 & -0.205 & $-7.299 *$ & 0.52 & $50.93^{*}$ \\
\hline Mediator: general well-being & -0.094 & -0.494 & $-14.714^{*}$ & & \\
\hline Dependent variable: psychological distress & & & & & \\
\hline
\end{tabular}

GHQ-12 scores of four and above indicates tendency of psychological distress. *statistical significance: $p<0.001$

physical exercise had higher scores for general well-being and lower scores on psychological distress.

\section{Testing for the mediation effect}

Subsequently, we performed multiple linear regression analysis to examine whether general well-being mediate the association between family functioning and psychological distress. Those variables of age, gender, marriage, hobby, sleeping time, sleep disturbance, self-rated health, life satisfaction, hemodialysis frequency, self-care ability, caregiver, coronary heart disease, brain hemorrhage and chronic obstructive pulmonary disease were entered as covariates. In the first step, the results indicated that family functioning was significantly associated with general well-being $(\mathrm{B}=0.819 ; \mathrm{t}=4.966, \mathrm{p}<0.001 ; \mathrm{F}=38.49$, $\mathrm{p}<0.001, \mathrm{R}^{2}=0.43$ ). In the second step, family functioning was significantly associated with psychological distress significantly $\left(\mathrm{B}=-0.291 ; \mathrm{t}=-8.889, \mathrm{p}<0.001 ; \mathrm{F}=31.02, \mathrm{p}<0.001, \mathrm{R}^{2}=0.38\right)$. In the third step, when we controlled for family functioning, general well-being was significantly associated with psychological distress $(\mathrm{B}=-0.214 ; \mathrm{t}=-0.205, \mathrm{p}<0.001 ; \mathrm{F}=50.93, \mathrm{p}<0.001$, $\mathrm{R}^{2}=0.52$ ). Data are shown in Table 4.

In addition, we used the PROCESS macro method (Model 4) further test the indirect effect of mediation using SPSS and by performing a bootstrap method. We calculated the 95\% CI based on a bootstrap analysis with 5,000 replications. The direct effects of family functioning on psychological distress (Effect $=-0.21,95 \% \mathrm{CI}=-0.27,-0.16$ ) was significant, as 0 was not contained in the $95 \% \mathrm{CI}$. The indirect effects of family functioning on psychological distress through general well-being (Effect=-0.08, 95\% CI=-0.11, -0.04) were also significant. Hence, we confirmed that general well-being partial mediates the association between family functioning and psychological distress.

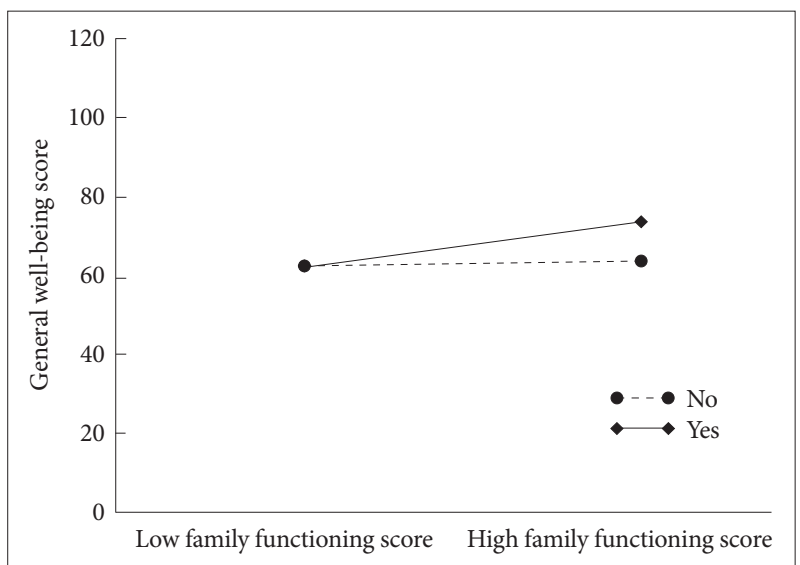

Figure 1. Exercise moderates the effect of family functioning on general well-being.

\section{Testing for the moderated mediation effect}

The moderated mediation model was based on the mediation model. This model was used to test for the ability of exercise to moderate the relationship between family functioning and psychological distress via general well-being. In Models 1 and 3 , the exercise variable had no moderating effect on the pathway since the interaction between family functioning and exercise was not significant. The exercise variable had a moderate effect on the pathway between family functioning and general well-being in model $2(B=0.974 ; t=3.004, p=0.003$; $\left.\mathrm{F}=36.909, \mathrm{p}<0.001, \mathrm{R}^{2}=0.440\right)$. The interaction term for family functioning and exercise was positively related to general wellbeing. Simple slope analyses were utilized to demonstrate the significant interaction of exercise and non-exercise (Figure 1). For individuals who did exercise, good family functioning was associated with a high level of general well-being $\left(\beta_{\text {simple }}=\right.$ $0.031, t=5.773, p<0.001)$. However, for individuals who did not exercise, the effect of family functioning was not significant ( $\left.\beta_{\text {simple }}=0.224, \mathrm{t}=0.814, \mathrm{p}=0.416\right)$. Data was shown in Table 5 .

We reconfirmed the moderated mediation model by em- 
Table 5. The moderating model effect of exercise on the relationship between family functioning and psychological distress

\begin{tabular}{|c|c|c|c|c|c|c|}
\hline Model & $\mathrm{B}$ & SE & $\beta$ & $\mathrm{t}$ & $\mathrm{R}^{2}$ & $\mathrm{~F}$ \\
\hline \multicolumn{7}{|c|}{ Model 1. Family functioning predicts psychological distress } \\
\hline Family functioning $\ddagger$ & -0.294 & 0.052 & -0.283 & $-5.621^{\dagger}$ & 0.311 & $9.912^{\dagger}$ \\
\hline Family functioning§ & -0.297 & 0.044 & -0.291 & $-6.769^{\dagger}$ & 0.398 & $20.407^{\dagger}$ \\
\hline Family functioning $\times$ Exercise ${ }^{\|}$ & 0.015 & 0.065 & 0.032 & 0.234 & 0.381 & $28.876^{\dagger}$ \\
\hline \multicolumn{7}{|c|}{ Model 2. Family functioning predicts general well-being } \\
\hline Family functioning ${ }^{\ddagger}$ & 0.172 & 0.249 & 0.032 & 0.692 & 0.412 & $15.389^{\dagger}$ \\
\hline Family functioning§ & 1.229 & 0.225 & 0.225 & $5.471^{\dagger}$ & 0.449 & $25.116^{\dagger}$ \\
\hline Family functioning $\times$ Exercise" & 0.974 & 0.324 & 0.392 & $3.004^{*}$ & 0.440 & $36.909^{\dagger}$ \\
\hline \multicolumn{7}{|c|}{ Model 3. Family functioning predicts psychological distress via general well-being } \\
\hline Family functioning ${ }^{\ddagger}$ & -0.275 & 0.044 & -0.265 & $-6.188^{\dagger}$ & \multirow{2}{*}{0.506} & \multirow{2}{*}{$20.899+$} \\
\hline General well-being ${ }^{\ddagger}$ & -0.112 & 0.010 & -0.576 & $-10.984^{\dagger}$ & & \\
\hline Family functioning§ & -0.192 & 0.041 & -0.188 & $-4.698^{\dagger}$ & \multirow{2}{*}{0.514} & \multirow{2}{*}{$30.339^{\dagger}$} \\
\hline General well-being§ & -0.086 & 0.008 & -0.458 & $-10.117^{\dagger}$ & & \\
\hline General well-being $\times$ Exercise $^{\|}$ & 0.015 & 0.011 & 0.243 & 1.430 & 0.521 & $48.049^{\dagger}$ \\
\hline
\end{tabular}

GHQ-12 scores of four and above indicates tendency of psychological distress. ${ }^{*}$ statistical significance: $p<0.05$, ${ }^{\dagger}$ statistical significance: $p<0.001$, łpresented as non-exercise group results, \$presented as exercise group results, "presented the result that was not split by the variable of exercise

ploying the PROCESS macro (Model 7) in SPSS, and demonstrated that the influence of family functioning on general wellbeing was moderated by exercise (Index $=-0.092, \mathrm{SE}=0.033$, $95 \% \mathrm{CI}=-0.159,-0.029)$. The conceptual framework of the moderated mediation model is shown in Figure 2. When the exercise variable was added to the model, there was a conditional direct effect of family functioning on general well-being that was significant (Effect $=-0.215, \mathrm{SE}=0.029, \mathrm{t}=-7.294$, $\mathrm{p}<0.001,95 \% \mathrm{CI}=-0.272,-0.157)$. The conditional indirect effect of family functioning on general well-being confirmed that exercise had a significant moderate effect on the indirect relationship between family functioning and psychological distress (Effect $=-0.112, \mathrm{SE}=0.022,95 \% \mathrm{CI}=-0.157-0.070$ ). In contrast, being not exercising had no significant effect on the relationship between family functioning and psychological distress (Effect $=-0.020, \mathrm{SE}=0.027,95 \% \mathrm{CI}=-0.074,0.035$ ).

\section{DISCUSSION}

There were four major findings in this study. First, there was a high prevalence of psychological distress in ESRD patients undergoing hemodialysis in this study. Second, family functioning, general well-being and physical exercise were associated with the occurrence of psychological distress. Third, family dysfunctionality may increase the risk of psychological distress, and it could affect psychological distress partially through general well-being. Fourth, exercise had a significant moderate effect on the relationship between family functioning and general well-being. For patients who did physical exercise, the effect of family dysfunctionality on general well-

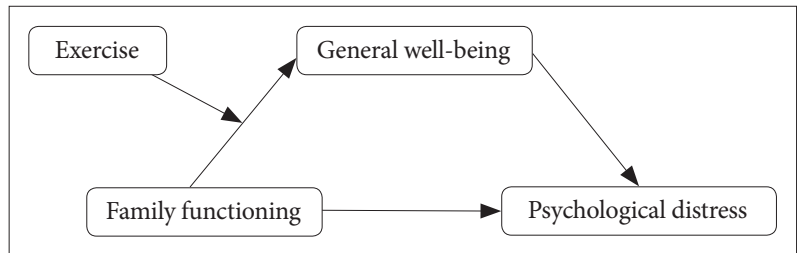

Figure 2. The conceptual framework of moderated mediation model.

being was weaker than for patients who did not do physical exercise. This study extends our knowledge about the relationships among exercise, family functioning, general wellbeing, and psychological distress.

Using the GHQ-12 with a cut-off score of four, this study found that the prevalence of psychological distress among ESRD patients was $72.3 \%$. The prevalence of psychological distress among ESRD patients was higher than that among the general population (19-40\%), ${ }^{44,45}$ cancer patient (approximately $30 \%){ }_{,}^{46}$ and stroke and hypertension patients (30$50 \%) .{ }^{47,48}$ The major reason for this result may be that ESRD is a disease that has a prolonged course and a high mortality rate,$^{49}$ combined with the type of treatment is traumatic. Although hemodialysis might prolong ESRD patient's survival, those patients might face a decline in physical function (e.g., pain, medical co-morbidities), and an increase in lifestyle limitations (e.g., diet, lower functional status, etc), which might impose psychological distress. ${ }^{50}$

The results of the correlation analyses indicated that there was an association among exercise, family functioning, general well-being, and psychological distress. The level of family functioning and general well-being were negatively correlat- 
ed with the risk of psychological distress. In contrast, the level of family functioning was positively correlated with general well-being level, which is in line with previous studies. ${ }^{15,51,52}$ A possible explanation of our findings could be that good family functioning may improve the level of general well-being and decrease the risk of psychological distress. Moreover, a high level of general well-being is associated with lower psychological distress among ESRD patients. In addition, our study showed that compared with patients who did not do physical exercise, patients who did physical exercise had a higher level of general well-being and lower risk of psychological distress. This finding indicated that exercise can regulate emotions, improve the level of general well-being, and decrease the risk of psychological distress of patients.

Simple mediation analyses suggested a significant indirect effect of general well-being, revealing that patients who were frequently exposed to a dysfunctional family had a low level of general well-being, which, in turn, can lead to psychological distress. The finding of this study was in line with previous studies. ${ }^{53,54}$ Edwards and Clarke ${ }^{53}$ have demonstrated that good family functioning was associated with lower levels of psychological distress, depression and anxiety. Bahremand et al. ${ }^{54}$ supposed that there was an indirect relationship between family functioning and mental health. Previous studies found that general well-being can mediate the relationship between other variables and mental health. ${ }^{16,17}$ The result of this study had demonstrated that general well-being mediated the relationship between family functioning and psychological distress, which verified the theory of "stimulus -- cognitive -- reaction." If the family is dysfunctional, the level of patients' general wellbeing will change and patients may be at risk for emotional distress and psychological problems. ${ }^{52}$

This research showed that exercise played a moderate role in the indirect relationship between family functioning and psychological distress. Specifically, exercise moderated the first phase of the indirect pathway, which meant that exercise has a moderating effect on the relationship between family functioning and general well-being. This validated the theories of mood-regulation and broaden-and-build of positive emotions. ${ }^{22,25}$ Patient's psychological distress may be a negative emotional adaptation for family dysfunctionality and low-level general well-being. As an important source of emotional support for ESRD patients, family functioning was a crucial factor affecting the patient's psychological health status. Exercise is an important outlet for emotion and may be a protective factor. It can increase patients' positive emotion to protect against adverse psychological outcomes. ${ }^{55}$ Exercise attenuated these negative effects of family dysfunctionality. ${ }^{56}$ For those patients who did physical exercise, family dysfunctionality had less impact on general well-being than it did for those patients who not do physical exercise. Exercise is an important factor for improving general well-being and decreasing the risk of psychological distress. Persistence in the exercising was also a protection against the psychological distress in patients. ${ }^{57}$ Strategies for appropriately increasing physical exercise play an important role in reducing the impact of dysfunctional family and increasing the level of general well-being in patients.

The cross-sectional survey design cannot determine the directionality of the observed relations, but our findings are still noteworthy. Given the family dysfunctionality can reduce the level of general well-being and increase the risk of psychological distress, family members and clinicians should pay more attention to the role of family functioning in the patient's psychological state. Family members of the patient can improve family functioning by improving family cohesion, intimacy and the like. Specifically, the family members of the patients can give more care, companionship and support to the patients in daily life so that the patients have more happiness from family. ESRD is a special chronic disease, and it limits the patient's ability to exercise when patient's condition is severe. Patients with better physical condition can insist on proper physical exercise, which can help patients attenuate the effects of negative events such as family dysfunctionality on well-being and reduce the risk of psychological distress.

\section{Acknowledgments}

We are grateful to everyone who participated in the survey. This study was supported by grants from the Health and Family Planning Commission of Jilin Province, China (Grant Number: 2017G018).

\section{Conflicts of Interest}

The authors have no potential conflicts of interest to disclose.

\section{Author Contributions}

Conceptualization: Xiumin Zhang, Qi Wang. Data curation: Wenjing Xiong, Xinwen Fan, Xia Guo, Nan Li. Formal analysis: Qi Wang. Funding acquisition: Xiumin Zhang. Investigation: Qi Wang, Xiangrong Li, Hong Shi, Shuang Zha. Methodology: Qi Wang, Zheng Ren. Project administration: Xiumin Zhang, Zheng Ren. Resources: Xiumin Zhang. Sofware: Qi Wang. Supervision: Xiumin Zhang, Hongiian Liu. Validation: Xiumin Zhang. Visualization: Qi Wang. Writing_original draf: Qi Wang. Writing_review \& editing: Xiumin Zhang, Hongian Liu, Minfu He.

\section{ORCID iDs}

$\begin{array}{ll}\text { Qi Wang } & \text { https://orcid.org/0000-0002-4787-3832 } \\ \text { Hongjian Liu } & \text { https://orcid.org/0000-0002-9571-1387 } \\ \text { Zheng Ren } & \text { https://orcid.org/0000-0002-9233-7414 } \\ \text { Wenjing Xiong } & \text { https://orcid.org/0000-0003-1267-2595 } \\ \text { Minfu He } & \text { https://orcid.org/0000-0002-5432-8998 } \\ \text { Nan Li } & \text { https://orcid.org/0000-0003-3037-4233 } \\ \text { Xinwen Fan } & \text { https://orcid.org/0000-0002-7292-3758 } \\ \text { Xia Guo } & \text { https://orcid.org/0000-0001-9581-8427 } \\ \text { Xiangrong Li } & \text { https://orcid.org/0000-0002-6258-0632 } \\ \text { Hong Shi } & \text { https://orcid.org/0000-0003-3776-498X } \\ \text { Shuang Zha } & \text { https://orcid.org/0000-0002-0148-2553 } \\ \text { Xiumin Zhang } & \text { https://orcid.org/0000-0003-3286-8667 }\end{array}$




\section{REFERENCES}

1. Chou MC, Ko CH, Chang JM, Hsieh TJ. Disruptions of brain structural network in end-stage renal disease patients with long-term hemodialysis and normal-appearing brain tissues. J Neuroradiol 2019; 46:256-262.

2. Thomas B, Wulf S, Bikbov B, Perico N, Cortinovis M, Courville De Vaccaro K, et al. Maintenance Dialysis throughout the World in Years 1990 and 2010. J Am Soc Nephrol 26:2621-2633.

3. Senanayake S, Gunawardena N, Palihawadana P, Suraweera C, Karunarathna R, Kumara P. Depression and psychological distress in patients with chronic renal failure: Prevalence and associated factors in a rural district in Sri Lanka. J Psychosom Res 2018;112:25-31.

4. Kopple JD, Shapiro BB, Feroze U, Kim JC, Zhang M, Li Y, et al. Hemodialysis treatment engenders anxiety and emotional distress. Clin Nephrol 2017;88:205-217.

5. Hudson JL, Moss-Morris R, Norton S, Picariello F, Game D, Carroll A, et al. Tailored online cognitive behavioural therapy with or without therapist support calls to target psychological distress in adults receiving haemodialysis: a feasibility randomised controlled trial. J Psychosom Res 2017;102:61-70.

6. Drayer RA, Piraino B, Reynolds CF 3rd, Houck PR, Mazumdar S, Bernardini J, et al. Characteristics of depression in hemodialysis patients: symptoms, quality of life and mortality risk. Gen Hosp Psychiatry 2006; 28:306-312.

7. Peterson RA, Kimmel PL, Sacks CR, Mesquita ML, Simmens SJ, Reiss D. Depression, perception of illness and mortality in patients with end-stage renal disease. Int J Psychiatry Med 1991;21:343-354.

8. Ozono S, Saeki T, Inoue S, Mantani T, Okamura H, Yamawaki S. Family functioning and psychological distress among Japanese breast cancer patients and families. Support Care Cancer 2005;13:1044-1050.

9. Ozono S, Saeki T, Mantani T, Ogata A, Okamura H, Nakagawa SI, et al. Psychological distress related to patterns of family functioning among Japanese childhood cancer survivors and their parents. Psychooncology 2010;19:545-552.

10. Lu C, Yuan L, Lin W, Ying Z, Pan S. Depression and resilience mediates the effect of family function on quality of life of the elderly. Arch Gerontol Geriatr 2017;71:34-42.

11. Kissane DW, Bloch S, Burns WI, Patrick JD, Wallace CS, Mckenzie DP. Perceptions of family functioning and cancer. Psychooncology 2010;3: 259-269.

12. Northouse LL, Mood D, Kershaw T, Schafenacker A, Mellon S, Walker J, et al. Quality of life of women with recurrent breast cancer and their family members. J Clin Oncol 2002;20:4050-4064.

13. Diener E. Assessing subjective well-being: progress and opportunities. Soc Indic Res 1994;31:103-157.

14. Keshvari M, Ebrahimi A, Abedi H. Relation between children's wellbeing and family function in children with thalassemia major in Isfahan in 2013. Glob J Health Sci 2016;8:170.

15. Coty MB, Wallston KA. Problematic social support, family functioning, and subjective well-being in women with rheumatoid arthritis. Women Health 2010;50:53-70.

16. Burns RA, Anstey KJ, Windsor TD. Subjective well-being mediates the effects of resilience and mastery on depression and anxiety in a large community sample of young and middle-aged adults. Aust N Z J Psychiatry 2011;45:240-248.

17. Gao T, Ding X, Chai J, Zhang Z, Zhang H, Kong Y, et al. The influence of resilience on mental health: the role of general well-being. Int J Nurs Pract 2017;23:e12535.

18. Wilhelm S. Cognitive psychology and emotional disorders. J Behav Ther Exp Psychiatry 1997;29:99-100.

19. Dunn AL, Trivedi MH, Kampert JB, Clark CG, Chambliss HO. Exercise treatment for depression. Am J Prev Med 2005;72:319-323.

20. Blumenthal JA, Babyak MA, Doraiswamy PM, Watkins L, Hoffman $\mathrm{BM}$, Barbour KA, et al. Exercise and pharmacotherapy in the treat- ment of major depressive disorder. Psychosom Med 2007;69:587-596.

21. DiLorenzo TM, Bargman EP, Stucky-Ropp R, Brassington GS, Frensch PA, LaFontaine T. Long-term effects of aerobic exercise on psychological outcomes. Prev Med 1999;28:75-85.

22. Fredrickson BL. The broaden-and-build theory of positive emotions. Philos Trans R Soc Lond B Biol Sci 2004;359:1367-1378.

23. Thompson RA. Emotional regulation and emotional development. Educ Psychol Rev 1991;3:269-307.

24. Gross JJ, Munoz RF. Emotion regulation and mental health. Clin Psychol 1995;2:151-164.

25. Stacey B. Changing moods: the psychology of mood and mood regulation. Aust Psychol 1998;33:158-159.

26. Zabora J, Brintzenhofeszoc K, Curbow B, Hooker C, Piantadosi S. The prevalence of psychological distress by cancer site. Psychooncology 2001;10:19-28.

27. Deimling GT, Bowman KF, Sterns S, Wagner LJ, Kahana B. Cancer-related health worries and psychological distress among older adult, long-term cancer survivors. Psychooncology 2010;15:306-320.

28. Hilari K, Northcott S, Roy P, Marshall J, Wiggins RD, Chataway J, et al. Psychological distress after stroke and aphasia: the first six months. Clin Rehabil 2010;24:181-190.

29. Kamlesh J, Rajesh K, Ajit A. Morbidity profile and its relationship with disability and psychological distress among elderly people in Northern India. Int J Epidemiol 2003;32:978-987.

30. Cheng TA, Williams P. The design and development of a screening questionnaire (CHQ) for use in community studies of mental disorders in Taiwan. Psychol Med 1986;16:415-422.

31. Goldberg DP. The Detection of Psychiatric Illness by Questionnaire: A Technique for the Identification and Assessment of Non-Psychotic Psychiatric Illness. Oxford: Oxford University Press; 1972.

32. Fryers T, Brugha T, Morgan Z, Smith J, Hill T, Carta M, et al. Prevalence of psychiatric disorder in Europe: the potential and reality of meta-analysis. Soc Psychiatry Psychiatr Epidemiol 2004;39:899-905.

33. Gupta S, Anderson R, Holt RI. Greater variation in affect is associated with lower fasting plasma glucose. Heliyon 2016;2:e00160.

34. Goldberg DP, Gater R, Sartorius N, Ustun TB, Piccinelli M, Gureje O, et al. The validity of two versions of the GHQ in the WHO study of mental illness in general health care. Psychol Med 2000;27:191-197.

35. Fu Y, Yu Y, Wang S, Kanu JS, You Y, Liu Y, et al. Menopausal age and chronic diseases in elderly women: a cross-sectional study in Northeast China. Int J Environ Res Public Health. 2016;13. pii: E936.

36. De Vries AM, Schulz T, Westerhuis R, Navis GJ, Niesing J, Ranchor $\mathrm{AV}$, et al. Goal disturbance changes pre/post-renal transplantation are related to changes in distress. Br J Health Psychol 2017;22:524-541.

37. Smilkstein G. The family APGAR: a proposal for a family function test and its use by physicians. J Fam Pract 1978;6:1231-1239.

38. Chau TT, Hsiao TM, Huang CT, Liu HW. A preliminary study of family Apgar index in the Chinese. Kao J Med Sci 1991;7:27.

39. Kim YS, Lee MJ, Suh YS, Kim DH. Relationship between family meals and depressive symptoms in children. Korean J Fam Med 2013;34: 206-212.

40. Caldwell CL, Horne AM, Davidson B, Quinn WH. Effectiveness of a multiple family group intervention for juvenile first offenders in reducing parent stress. J Child Fam Stud 2007;16:443-459.

41. Jianhua D. Results and analysis of the general well-being schedule in Chinese college students. China J Clin Psychol 1996;4:56-57.

42. Fazio AF. A concurrent validational study of the NCHS General WellBeing Schedule. Vital Health Stat 1977;73:1-53.

43. Taylor JE, Ii WSCP, Haddock CK, Blackburn GL, Heber D, Heymsfield SB, et al. Psychometric characteristics of the General Well-Being Schedule (GWB) with African-American women. Qual Life Res 2003; 12:31-39.

44. Serrano-Aguilar P, Ramallo-Fariña Y, Trujillo-Martín Mdel M, Muñoz-Navarro SR, Perestelo-Perez L, de las Cuevas-Castresana C. The relationship among mental health status (GHQ-12), health related 
quality of life (EQ-5D) and health-state utilities in a general population. Epidemiol Psichiatr Soc 2009;18:229-239.

45. Tang F, Byrne M, Qin P. Psychological distress and risk for suicidal behavior among university students in contemporary China. J Affect Disord 2018;228:101-108.

46. Singer S, Das-Munshi J, Brähler E. Prevalence of mental health conditions in cancer patients in acute care--a meta-analysis. Ann Oncol 2010;21:925-930.

47. Crichton SL, Bray BD, Mckevitt C, Rudd AG, Wolfe CD. Patient outcomes up to 15 years after stroke: survival, disability, quality of life, cognition and mental health. J Neurol Neurosurg Psychiatry 2016; 87:1091-1098.

48. Kretchy IA, Owusu-Daaku FT, Danquah SA. Mental health in hypertension: assessing symptoms of anxiety, depression and stress on antihypertensive medication adherence. Int J Ment Health Syst 2014;8:25.

49. Landray MJ, Emberson JR, Blackwell L, Dasgupta T, Zakeri R, Morgan MD, et al. Prediction of ESRD and death among people with CKD: the Chronic Renal Impairment in Birmingham (CRIB) prospective cohort study. Am J Kidney Dis 2010;56:1082-1094.

50. Neu S, Kjellstrand CM. Stopping long-term dialysis. An empirical study of withdrawal of life-supporting treatment. N Engl J Med 1986;
314:14-20.

51. Cheng Y, Zhang L, Wang F, Zhang P, Ye B, Liang Y. The effects of family structure and function on mental health during China's transition: a cross-sectional analysis. BMC Fam Pract 2017;18:59.

52. Damodaran D. Road to mental health: from personality through subjective well-being. Int J Adv Nur Manage 2014;2:1-3.

53. Edwards B, Clarke V. The psychological impact of a cancer diagnosis on families: The influence of family functioning and patients' illness characteristics on depression and anxiety. Psychooncology 2010;13: 562-576.

54. Bahremand M, Rai A, Alikhani M, Mohammadi S, Shahebrahimi K, Janjani P. Relationship between family functioning and mental health considering the mediating role of resiliency in type 2 diabetes mellitus patients. Glob J Health Sci 2015;7:254-259.

55. Berger BG, Motl RW. Exercise and mood: a selective review and synthesis of research employing the profile of mood states. J Appl Sport Psychol 2000;12:69-92.

56. Bernstein EE, Mcnally RJ. Acute aerobic exercise helps overcome emotion regulation deficits. Cogn Emot 2017;31:1-10.

57. Diehl JJ, Choi HM. Exercise: the data on its role in health, mental health, disease prevention, and productivity. Prim Care 2008;35:803-816. 